\title{
PENGEMBANGAN WEB SERVICE MODUL MAHASISWA PADA SISTEM INFORMASI AKADEMIK UNIVERSITAS NEGERI JAKARTA
}

\author{
Febrianto Widyoutomo ${ }^{1}$, Hamidillah Ajie $^{2}$, Widodo ${ }^{3}$ \\ ${ }^{1}$ Mahasiswa Prodi PendidikanTeknik Informatika dan Komputer, Teknik Elektro, FT - UNJ \\ ${ }^{2,3}$ Dosen Prodi Pendidikan Teknik Informatika dan Komputer, Teknik Elektro, FT - UNJ \\ ${ }^{1}$ widyoutomof@gmail.com, ${ }^{2}$ hamidillah@unj.ac.id, ${ }^{3}$ widodo@unj.ac.id
}

\begin{abstract}
Abstrak
Perkembangan teknologi sebagai bagian dari inovasi yang dapat memberikan banyak kemudahan dalam berbagai bidang. Penerapan teknologi dalam bidang pendidikan mendorong terciptanya sistem informasi yang dapat mengelola berbagai data, baik data akademik maupun non-akademik. Universitas Negeri Jakarta(UNJ) menjadi salah satu perguruan tinggi yang memanfaatkan sistem informasi sebagai sarana pengelola data akademik yang dinamakan SIAKAD UNJ. SIAKAD UNJ saat ini tidak memiliki arsitektur sistem yang maksimal, sehingga belum bersifat adaptif terhadap pengembangan dan pembaruan fitur di dalam sistem. Tujuan dari penelitian ini adalah untuk menghasilkan web service yang dapat digunakan dalam SIAKAD UNJ dan memiliki sifat adaptif terhadap perubahan-perubahan di masa mendatang. Pengembangan web service SIAKAD UNJ dengan metode spiral menggunakan framework Express.js dan menghasilkan 25 endpoint. Pengujian dengan metode unit testing terhadap 25 endpoint menggunakan aplikasi bernama Postman. Hasil pengujian menunjukkan bahwa 25 endpoint yang diuji berfungsi dengan baik, dan layak digunakan sebagai sisi backend yang akan digabungkan dengan sisi frontend untuk menjadi aplikasi SIAKAD UNJ yang utuh.
\end{abstract}

Kata kunci : sistem informasi akademik, web service, metode spiral, express, endpoint, unit testing.

\section{Pendahuluan}

\subsection{Latar Belakang}

Setiap inovasi hadir untuk memberikan manfaat bagi kehidupan manusia. Teknologi sebagai bagian dari inovasi yang dapat memberikan banyak kemudahan, serta sebagai penunjang hadirnya inovasi-inovasi lain. Oleh karenanya, teknologi menjadi hal yang tidak bisa dihindari dalam kehidupan ini. Saat ini, teknologi dimanfaatkan dalam berbagai bidang, seperti bidang pendidikan, administrasi dan lain-lain.

Teknologi yang berkembang mempunyai pengaruh terhadap bidang pendidikan, salah satunya yaitu perguruan tinggi. Penerapan teknologi pada perguruan tinggi berupa sistem untuk mengelola layanan informasi dan administrasi akademik, layanan informasi kurikulum, layanan penerimaan peserta didik baru dan banyak lainnya agar lebih terorganisir, efektif, dan efisien.

Universitas Negeri Jakarta (UNJ) menjadi salah satu perguruan tinggi negeri di Indonesia yang dalam perkembangan penyelenggaraan program pendidikan mulai dari jenjang Diploma, Sarjana, Magister hingga Doktor. Tidak bisa dipungkiri untuk dapat memberikan informasi dan layanan sebagai penunjang keberlangsungan akademik yang terorganisir, efektif dan efisien, Universitas Negeri
Jakarta memanfaatkan teknologi untuk mengatasi hal itu. Maka dibuatlah Sistem Informasi Akademik (SIAKAD) pada tahun 1980-an.

Berdasarkan hasil wawancara kepada pimpinan dan karyawan Unit Pelayanan Teknis Teknologi Informasi dan Komunikasi (UPT TIK) UNJ, SIAKAD UNJ saat itu berfungsi sebagai penyimpanan data akademik dalam bentuk digital. Seiring berjalannya waktu, pada tahun 2000 SIAKAD UNJ telah menggunakan sistem berbasis IBM AS400 yang fungsinya mampu mengelola data akademik, seperti pengisian jadwal kuliah, pengisian Kartu Rencana Studi (KRS) dan penyimpanan nilai akhir semester mahasiswa.

Pengembangan SIAKAD UNJ berbasis web yang memiliki banyak fitur untuk berbagai pengguna ini akan dilakukan secara bertahap, salah satunya membagi secara modular sesuai dengan tugas dan wewenang dari masing-masing pengguna, seperti modul mahasiswa, modul dosen, modul administrasi program studi dan lain sebagainya. Tujuan dibuatnya modul-modul ini adalah membuat pengembangan terfokus pada bagian-bagian kecil sehingga pengembangan menjadi lebih sederhana dan efisien serta yang paling utama untuk memudahkan pembuatan dokumentasi atas pengembanganpengembangan yang terjadi. 
Modul Mahasiswa menjadi komponen penting dalam SIAKAD UNJ, karena proses akademik ini menyangkut administrasi mahasiswa dalam pembelajaran tiap semesternya. Modul ini ada untuk mahasiswa memproses administrasi akademik secara digital. Adapun layanan yang diberikan di dalam modul mahasiswa, yaitu pengelolaan biodata mahasiswa, pengisian KRS, unduh KHS pada tiap semester yang telah diselesaikan dan bentuk administrasi akademik lainnya.

Desain arsitektur SIAKAD UNJ saat ini belum membagi sistem menjadi dua sisi, yaitu sisi backend dan sisi frontend. Desain semacam ini mempunyai tingkat adaptasi aplikasi web yang rendah, karena apabila ada pengembangan dan pembaruan terhadap fitur-fitur SIAKAD UNJ akan mempengaruhi aplikasi secara keseluruhan dikarenakan sisi presentation dan business logic ada pada satu kesatuan dan akan saling mempengaruhi. Atas dasar tersebut, maka terdapat beberapa pilihan alternatif untuk mengembangkan aplikasi web yang memiliki adaptasi terhadap perubahan dan pengembangan fitur-fitur di dalam SIAKAD UNJ salah satunya membuat arsitektur aplikasi menjadi tiga sisi, yaitu sisi frontend, sisi backend, dan sisi database.

Web service yang menjadi peran utama dalam backend adalah sistem pertukaran informasi dengan memanfaatkan jaringan internet untuk interaksi antar aplikasi dan perangkat dengan format standar seperti text, eXtensible Markup Language (XML), JavaScript Object Notation (JSON). Web service adalah sebuah sistem yang didesain untuk mendukung interoperabilitas interaksi mesin ke mesin melalui sebuah jaringan. Web service dapat diartikan juga sebuah metode pertukaran data tanpa memperhatikan di mana sebuah database ditanamkan, dalam bahasa apa sebuah aplikasi yang menggunakan data tersebut, dan di platform apa sebuah data digunakan.

Pemanfaatan web service pada SIAKAD UNJ akan membuat aplikasi web SIAKAD UNJ menjadi lebih adaptif terhadap pengembangan dan pembaruan fitur-fitur. Dengan menggunakan web service memungkinkan perbaikan akan sistem tidak akan memengaruhi sisi frontend, sehingga memudahkan dalam sisi perawatan sistem. Web service sebagai metode pertukaran data yang tidak memperhatikan di platform apa sebuah data digunakan, atau dalam kata lain dapat digunakan secara cross platform.

Berdasarkan pemahaman di atas, penulis mencoba mengangkat permasalahan tersebut ke dalam studi penelitian yang berjudul "Pengembangan Web Service Modul Mahasiswa Sistem Informasi Akademik Universitas Negeri Jakarta". Harapannya agar pengembangan web Sistem Informasi Akademik Universitas Negeri Jakarta memiliki tingkat adaptasi yang baik kedepannya.

\subsection{Identifikasi Masalah}

Berdasarkan latar belakang yang telah dibahas sebelumnya, identifikasi masalah pada penelitian ini adalah :

1. Sistem Informasi Akademik Universitas Negeri Jakarta belum memiliki arsitektur sistem yang maksimal, sehingga belum bersifat adaptif terhadap pengembangan dan pembaruan fitur di dalam sistem.

2. Masih menyatunya semua sistem untuk berbagai user yang memungkinkan fokus akan terbagi dalam pengembangan aplikasi.

3. Sistem Informasi Akademik Universitas Negeri Jakarta masih menerapkan desain arsitektur yang hanya membagi sistem menjadi dua sisi, yaitu interface dan database dalam satu kesatuan sehingga akan mempersulit dalam pengembangan sistem jika ada pembaruan pada sistem.

\subsection{Pembatasan Masalah}

Melihat luasnya lingkup permasalahan, agar memperoleh hasil penelitian yang optimal dan terfokus, maka pembatasan masalah sangat penting untuk dilakukan. Penelitian dibatasi pada:

1. Pada penelitian ini tahapan yang akan menjadi pokok bahasan dari rangkaian Sistem Informasi Akademik Universitas Negeri Jakarta Modul Mahasiswa.

2. Penelitian ini tidak akan menghasilkan daftar kebutuhan perangkat lunak, namun menggunakan dokumen requirement milik UPT TIK UNJ.

3. Penelitian ini akan menghasilkan web service berupa endpoint-endpoint dan tidak menghasilkan aplikasi web SIAKAD yang siap digunakan dengan menggunakan basis data berdasarkan standar PDDikti.

\subsection{Rumusan Masalah}

Berdasarkan latar belakang masalah, identifikasi, dan pembatasan masalah, maka perumusan masalah yang akan dibahas pada penelitian ini adalah: Bagaimana mengembangkan web service yang dapat digunakan dalam pengembangan Modul Mahasiswa pada Sistem Informasi Akademik Universitas Negeri Jakarta?

\subsection{Tujuan Penelitian}

Tujuan yang diharapkan akan dicapai pada penelitian adalah untuk menghasilkan web service yang dapat digunakan dalam pengembangan aplikasi modul mahasiswa SIAKAD Universitas Negeri Jakarta dan memiliki tingkat adaptasi yang baik terhadap perubahan-perubahan di masa mendatang.

\subsection{Manfaat Penelitian Tujuan Penelitian}


1. Secara teoritis, hasil dari penelitian ini diharapkan dapat dimanfaatkan sebagai referensi dan masukan bagi perkembangan ilmu pengembangan aplikasi web khususnya web programming.

2. Secara praktis, hasil dari penelitian ini diharapkan dapat digunakan sebagai sebuah backend yang akan diimplementasikan dengan frontend sehingga menghasilkan aplikasi web Sistem Informasi Akademik Universitas Negeri Jakarta secara utuh.

\section{Dasar Teori}

\subsection{Sistem Informasi Akademik Universitas Negeri Jakarta}

Sistem Informasi Akademik Universitas Negeri Jakarta (SIAKAD UNJ) adalah sistem aplikasi berbasis web milik Universitas Negeri Jakarta (UNJ) yang dijadikan alat untuk mengelola kegiatan akademik di lingkup universitas. SIAKAD UNJ ada guna untuk membuat proses administrasi dan berbagai kebutuhan akademik di UNJ secara digital dan dapat diakses di mana pun.

SIAKAD UNJ menjadi tempat penyimpanan informasi akademik bagi mahasiswa, dosen, administrator program studi seperti biodata mahasiswa, Kartu Rencana Studi (KRS), Kartu Hasil Studi (KHS), Daftar Hasil Studi (DHS), jadwal kuliah, pembayaran, pengisian nilai, dan sebagainya. SIAKAD UNJ mengelola data akademik secara keseluruhan dan terintegrasi satu sama lain antara data mahasiswa, data dosen dan data program studi, sehingga setiap perubahan terjadi pada data akan berpengaruh terhadap data lainnya secara langsung. Data yang ada pada SIAKAD akan menjadi informasi akademik pusat bagi mahasiswa, dosen, administrator program studi dan fakultas, serta pimpinan universitas, sehingga dengan adanya SIAKAD ini dapat membuat data tersimpan secara rapi dan terstruktur.

\subsection{Modul Mahasiswa SIAKAD UNJ}

Modul Mahasiswa menjadi komponen penting dalam SIAKAD UNJ, karena proses akademik ini menyangkut administrasi mahasiswa dalam pembelajaran tiap semesternya. Modul ini ada untuk mahasiswa memproses administrasi akademik secara digital. Adapun layanan yang diberikan di dalam modul mahasiswa, yaitu: (a) pengelolaan biodata mahasiswa; (b) pengelolaan akun; (c) pengelolaan KRS, seperti pengisian pada awal semester, pantau dan unduh pada tiap semester yang diikuti; (d) pantau dan unduh KHS pada tiap semester yang telah diselesaikan; (e) pantau dan unduh DHS yang memperlihatkan daftar keseluruhan hasil dari seluruh aktivitas akademik selama menjadi mahasiswa UNJ; (f) pantau jadwal kuliah tiap semester; (h) pendaftaran Praktik Keterampilan Mengajar (PKM); (i) pengisian evaluasi perkuliahan di akhir semester.

\subsection{Sisi Backend}

Backend adalah sisi yang bertolak belakang dengan sisi frontend yang berhadapan langsung dengan client, dimana backend merupakan server side yang mengelola data dan menjalankan business logic sebuah aplikasi. Backend bertindak sebagai arsitek yang merancang sistem dan teknologi web. Backend bertanggung jawab akan program yang bekerja pada server agar mengirimkan informasi ke browser pengguna setiap kali pengguna memintanya melalui HTTP request. Sisi backend juga yang berinteraksi langsung dengan database, sehingga frontend hanya akan menerima informasi yang bersumber dari database melalui backend.

\subsection{Service Oriented Architecture (SOA)}

Service Oriented Architecture (SOA) merupakan sekumpulan fungsi, prosedur atau proses yang akan memberi respons jika diminta oleh sebuah client. SOA adalah salah satu bentuk arsitektur teknologi yang mengikuti prinsip-prinsip service computing platform dengan membawa konsep, teknologi, dan tantangan baru. Menurut Thomas Erl konsep service oriented ini melakukan pendekatan dengan membagi masalah besar menjadi sekumpulan service kecil yang bertujuan untuk menyelesaikan permasalahan tertentu (Erl,2008).

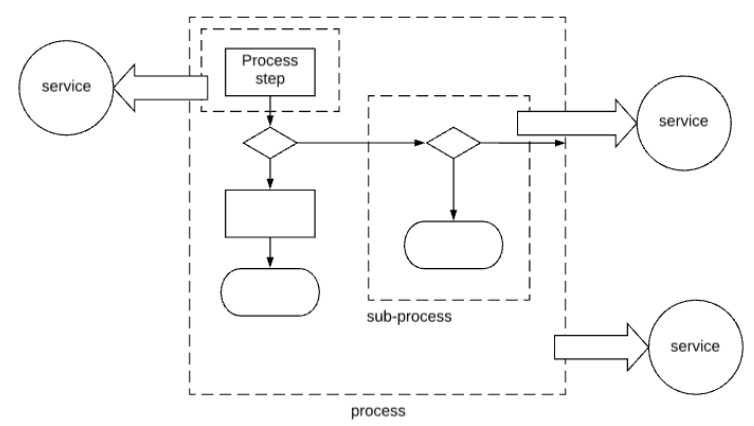

Gambar 2.1 Enkapsulasi business process dengan service

\subsection{Web Service Restful}

Web service adalah sistem pertukaran informasi berbasis eXtensible Markup Language (XML) atau JavaScript Object Notation (JSON) dengan memanfaatkan jaringan internet untuk interaksi antar aplikasi dan perangkat. Teknologi ini menjadi standar yang diadopsi oleh banyak vendor perangkat lunak, karena memiliki standar terbuka. Standar terbuka ini yang memungkinkan aplikasi web service yang diimplementasi oleh vendor berbeda dapat berkomunikasi satu sama lain (Erl, 2008:56).

Web service memiliki dua bentuk, yaitu Simple Object Access Protocol (SOAP) dan 
Representational State Transfer (REST). SOAP dan REST memiliki kesamaan di antaranya, sama-sama digunakan metode pertukaran pesan dan data dalam komunikasi dengan web service dan sama-sama menggunakan protokol web Hypertext Transfer Protocol (HTTP) dan Hypertext Transfer Protocol Secure (HTTPS). Namun, REST relatif lebih hemat dalam penggunaan bandwidth, karena markupmarkup ekstra seperti XML dapat diganti dengan JSON, sehingga kini mulai beralih menggunakan REST.

\subsection{Framework}

Menurut Wardana (2016:3), framework adalah kumpulan perintah atau fungsi dasar yang membentuk aturan-aturan tertentu yang saling berinteraksi satu sama lain sehingga dalam pembuatan aplikasi kita harus mengikuti aturan dari framework tersebut. Framework yang dimaksud adalah kumpulan dari beberapa fungsi yang dibuat oleh orang atau perusahaan yang berguna untuk memudahkan pengembang dalam mengurangi waktu pembuatan sebuah aplikasi.

\subsection{Express.js}

Node.js adalah platform sisi server dibangun di mesin JavaScript V8 Google Chrome (V8 Engine) yang dikembangkan oleh Ryan Dahl pada tahun 2009. Node.js adalah aplikasi open source yang sepenuhnya gratis dan digunakan oleh ribuan developer di seluruh dunia untuk mengembangkan aplikasi sisi server dan jaringan. Node.js adalah sebuah environment runtime dari JavaScript. Environment runtime dari Node.js mencakup semua yang dibutuhkan pengembang web untuk menjalankan program yang ditulis dalam JavaScript (Nodejs).

Express.js adalah framework yang bekerja pada aplikasi Node.js yang minimalis dan fleksibel. Express.js juga memiliki dokumentasi yang lengkap dan penggunaannya yang cukup mudah, dapat membuat kita mengembangkan berbagai produk seperti aplikasi web ataupun RESTful API. Express.js pun dapat digunakan menjadi pijakan untuk membangun web framework yang lebih kompleks seperti sails.js, MEAN (MongoDB, Express.js, Angular.js, Node.js) dan MERN (MongoDB, Express.js, React.js, Node.js).

Express.js memiliki beberapa keunggulan yang membuatnya populer dikalangan developer web, seperti (a) mendukung pembuatan middleware yang berperan menyediakan mekanisme penyaringan HTTP request yang masuk ke aplikasi dengan kata lain setiap kali ada request masuk maka akan difilter oleh Middleware; (b) mendukung berbagai HTTP verb seperti POST, GET, PUT, DELETE, OPTION, HEAD, dan lainnya; (c) express.js memberikan layanan untuk dapat memilih template engine yang diperlukan; (d) express.js dapat memanajemen file statik seperti CSS dan Javascript; (e) express.js mempunyai sifat fleksibel sehingga sangat bebas untuk dikostumisasi. Contoh potongan program dari express.js ditunjukkan pada Gambar 2.2.

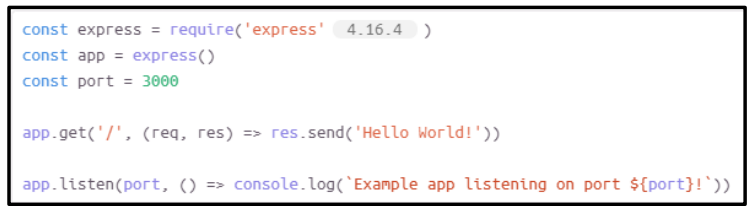

Gambar 2.2 Potongan program express.js

\subsection{JSON}

JavaScript Object Notation (JSON) adalah format pertukaran data yang ringan, mudah dibaca dan ditulis oleh manusia, serta mudah diterjemahkan dan dibuat (generate) oleh komputer. Format ini dibuat berdasarkan bagian dari Bahasa Pemrograman JavaScript, Standar ECMA-262 Edisi ke-3 Desember 1999. JSON merupakan format teks yang tidak bergantung pada bahasa pemrograman apapun karena menggunakan gaya bahasa yang umum digunakan oleh programmer keluarga $\mathrm{C}$ termasuk $\mathrm{C}$, $\mathrm{C}++, \mathrm{C} \#$, Java, JavaScript, Perl, Phyton dan lain-lain. Oleh karena sifat-sifat tersebut, menjadikan JSON ideal sebagai bahasa pertukaran data (json.org).

\subsection{Pengembangan Web Service dengan Metode Spiral}

Dalam mengembangkan perangkat lunak terdapat beberapa metodologi yang dapat digunakan, salah satunya yaitu metode Spiral yang akan digunakan dalam mengembangkan web service pada penelitian ini. Metode Spiral ini dikemukakan pertama oleh Barry Boehm pada tahun 1988 dengan jurnalnya yang berjudul A Spiral Model of Software Development and Enchancement. Metode Spiral adalah metode yang menggabungkan antara sifat iterative metode Prototyping dan sifat linear metode Waterfall dengan penekanan yang tinggi pada analisis risiko tiap tahapannya. Dalam tiap iterasinya, proses pengembangan perangkat lunak mengikuti tahaptahap fase linear di mana perangkat lunak akan dibuat prototype (incomplete model) dan pada akhir tiap fasenya, pengembang akan melakukan evaluasi bersama dengan user.

\section{Metodologi}

Penelitian ini menggunakan satu buah personal computer dan perangkat lunak untuk pengembangan web service, dengan spesifikasi perangkat keras dan perangkat lunak yang dapat dilihat pada Tabel 3.1 dan Tabel 3.2. Penelitian ini dilakukan dengan menggunakan hasil wawancara pimpinan dan karyawan UPT TIK UNJ. Sehingga didapat dokumentasi berupa daftar requirement. 
Tabel 3.1 Daftar Perangkat Keras

\begin{tabular}{|l|l|}
\hline \multicolumn{1}{|c|}{ Perangkat Keras } & \multicolumn{1}{c|}{ Spesifikasi } \\
\hline Prosesor & $\begin{array}{l}\text { Intel Core i5-7500 berkecepatan } \\
3.4 \mathrm{GHz} .\end{array}$ \\
\hline RAM & DDR4 8GB \\
\hline Harddisk & 1 TB \\
\hline Display & NVIDIA GeForce GTX 1050 Ti \\
\hline
\end{tabular}

Tabel 3.2 Daftar Perangkat Lunak

\begin{tabular}{|l|l|}
\hline \multicolumn{1}{|c|}{ Perangkat Lunak } & \multicolumn{1}{c|}{ Fungsi } \\
\hline Windows 10 64-bit & Sistem Operasi \\
\hline Microsoft Office 365 & Pengolah Kata \\
\hline $\begin{array}{l}\text { Visual Studio Code } \\
\text { Version: 1.33.1 }\end{array}$ & Text Editor \\
\hline Node.Js Version: 10.2.0 & $\begin{array}{l}\text { Node.Js sebagai web } \\
\text { server }\end{array}$ \\
\hline Postman Version: 6.7.3 & $\begin{array}{l}\text { Aplikasi Postman Native } \\
\text { dari Google sebagai } \\
\text { media testing }\end{array}$ \\
\hline
\end{tabular}

Penelitian ini dilakukan dengan menggunakan metode Spiral yang merupakan gabungan antara sifat iterative metode Prototyping dan sifat linear metode Waterfall dengan penekanan yang tinggi pada analisis risiko tiap tahapannya. Secara garis besar, metode penelitian yang akan dilaksanakan seperti diagram alir di bawah ini:

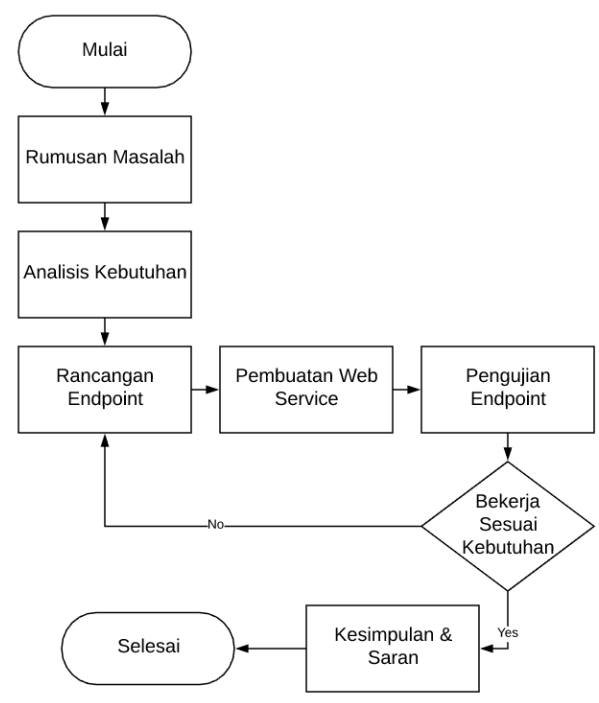

Gambar 2. Alur Penelitian

Proses pertama dalam penelitian ini adalah merumuskan masalah yang dipaparkan pada bahasan sebelumnya. Setelah itu, melakukan analisis kebutuhan berdasarkan dokumentasi yang telah dibuat oleh tim UPT TIK, Hafidz Arief Raharjo untuk melihat kebutuhan data yang ada dan mengelompokkan sesuai kebutuhan yang membutuhkan endpoint dan tidak membutuhkan endpoint.
Setelah dilakukan analisis kebutuhan, selanjutnya adalah melakukan perancangan web service sesuai dengan kebutuhan dari sistem yang dibuat menjadi endpoint-endpoint. Setelah merancang, selanjutnya membangun web service sesuai dengan hasil rancangannya dan lakukan pengujian menggunakan Postman untuk endpointendpoint yang telah dibuat. Jika masih memiliki kesalahan, maka dilihat kembali rancangannya dan hasil script koding untuk ditelusuri kesalahannya, karena kesalahan bisa terjadi pada rancangan yang tidak sesuai atau logika yang kurang tepat. Setelah semua selesai dan web service dinyatakan berhasil dan layak, selanjutnya dilakukan penarikan kesimpulan dan saran.

Pengujian menggunakan metode unit testing yaitu pengujian yang dilakukan pada masing-masing endpoint yang dihasilkan pada saat proses pengembangan web service. Pengujian ini dilakukan untuk mengetahui apakah web service berfungsi dengan baik sesuai dengan requirement yang telah ditentukan secara spesifik satu persatu fungsi dari endpoint-endpoint yang telah dibuat.

Tabel 3.1 Daftar Endpoint dengan Menggunakan $U R L$

http://localhost/mahasiswa/siakad/public/api/

\begin{tabular}{|c|c|c|c|}
\hline No & Requirement & Endpoint & $\begin{array}{c}\text { Tipe } \\
\text { Request }\end{array}$ \\
\hline 1 & Login & /user/login & POST \\
\hline 2 & $\begin{array}{l}\text { Menampilkan } \\
\text { pertanyaan } \\
\text { keamanan } \\
\text { (captcha) } \\
\end{array}$ & $\begin{array}{l}\text { /get- } \\
\text { captcha }\end{array}$ & GET \\
\hline 3 & $\begin{array}{l}\text { Menampilkan } \\
\text { daftar nilai } \\
\text { beserta bobot } \\
\text { nilai }\end{array}$ & $\begin{array}{l}\text { /ref- } \\
\text { bobot/ }\end{array}$ & GET \\
\hline 4 & $\begin{array}{l}\text { Menampilkan } \\
\text { daftar provinsi }\end{array}$ & $\begin{array}{l}\text { /ref- } \\
\text { provinsi/ }\end{array}$ & GET \\
\hline 5 & $\begin{array}{l}\text { Menampilkan } \\
\text { daftar } \\
\text { kota/kabupaten }\end{array}$ & /ref-kota/ & GET \\
\hline 6 & $\begin{array}{l}\text { Menampilkan } \\
\text { daftar kecamatan }\end{array}$ & $\begin{array}{l}\text { /ref- } \\
\text { kecamatan } \\
\text { / }\end{array}$ & GET \\
\hline 7 & $\begin{array}{l}\text { Menampilkan } \\
\text { daftar pekerjaan }\end{array}$ & $\begin{array}{l}\text { /ref- } \\
\text { pekerjaan/ }\end{array}$ & GET \\
\hline 8 & $\begin{array}{l}\text { Menampilkan } \\
\text { daftar } \\
\text { penghasilan }\end{array}$ & $\begin{array}{l}\text { /ref- } \\
\text { penghasila } \\
\text { n/ }\end{array}$ & GET \\
\hline 9 & $\begin{array}{l}\text { Menampilkan } \\
\text { daftar pendidikan }\end{array}$ & $\begin{array}{l}\text { /ref- } \\
\text { pendidikan }\end{array}$ & GET \\
\hline
\end{tabular}




\begin{tabular}{|l|l|l|l|}
\hline 10 & $\begin{array}{l}\text { Mengubah } \\
\text { password akun }\end{array}$ & $\begin{array}{l}\text { /user/uba } \\
\text { h- } \\
\text { password }\end{array}$ & POST \\
\hline
\end{tabular}

Pengujian (endpoint) fungsional dilakukan dengan proses skenario yang telah ditentukan seperti pada Tabel 3.2 - Tabel 3.3 menggunakan tool Postman.

Tabel 3.2 Pengujian Fungsional pada Endpoint Login

\begin{tabular}{|c|c|c|l|}
\hline No & Endpoint & Skenario & \multicolumn{1}{|c|}{ Respon } \\
\hline \multirow{2}{*}{1} & \multirow{2}{*}{ /user/login } & Sukses & $\begin{array}{l}\text { Menampilkan data } \\
\text { token dan status } \\
\text { respon 200 }\end{array}$ \\
\cline { 3 - 4 } & & Error & $\begin{array}{l}\text { Status respon 400 } \\
\text { dan pesan password } \\
\text { salah }\end{array}$ \\
\cline { 3 - 4 } & & $\begin{array}{l}\text { Status respon 500 } \\
\text { Internal server error }\end{array}$ \\
\hline
\end{tabular}

Tabel 3.5 Pengujian Fungsional pada Endpoint Menampilkan Pertanyaan Keamanan (Captcha)

\begin{tabular}{|c|c|c|l|}
\hline No & Endpoint & Skenario & \multicolumn{1}{|c|}{ Respon } \\
\hline \multirow{2}{*}{1} & $\begin{array}{c}\text { /get- } \\
\text { captcha }\end{array}$ & Sukses & $\begin{array}{l}\text { Menampilkan } \\
\text { pertanyaan beserta } \\
\text { jawaban dan status } \\
\text { respon 200 }\end{array}$ \\
\cline { 3 - 4 } & & Error & $\begin{array}{l}\text { Status respon 500 } \\
\text { Internal server error }\end{array}$ \\
\hline
\end{tabular}

\section{Hasil dan Analisis}

\subsection{Deskripsi Hasil Penelitian}

Produk yang dikembangkan menghasilkan 25 buah endpoint. Setiap endpoint dikembangkan dalam beberapa proses, yaitu: 1) penentuan data yang akan digunakan; 2) penentuan algoritma; 3 ) penulisan kode program; dan 4) pengujian terhadap endpoint. Pengembangan endpoint dilakukan menggunakan model spiral hingga berhasil dikembangkan dengan baik tanpa kesalahan sesuai dengan target pembuatan produk. Dan tidak lupa memperhatikan pesan yang akan dikirimkan agar memudahkan pihak pengembang frontend dalam menerima endpoint yang dikirimkan.

Setelah pengembangan terhadap 25 endpoint yang sudah dibuat, menunjukkan proses iterasi yang berbeda-beda. Dari 25 endpoint tersebut, requirement "menambahkan mata kuliah ke dalam kartu rencana studi mahasiswa" memiliki jumlah iterasi terbanyak yaitu 6 kali iterasi. Hal itu disebabkan oleh banyaknya hal yang harus diperhatikan, seperti memeriksa ketersediaan mata kuliah untuk seorang mahasiswa, memeriksa jumlah SKS maksimal yang dapat diambil mahasiswa, memeriksa kuota dari suatu kode seksi, dan memeriksa mata kuliah apakah sudah diambil atau belum. Sedangkan requirement referensi, seperti referensi pekerjaan, pendidikan, penghasilan, dan wilayah memiliki jumlah iterasi minimum yaitu 2 kali iterasi. Jumlah iterasi menunjukkan pada pengembangan enpoint-enpoint tersebut dipengaruhi oleh banyaknya hal yang harus diperhatikan untuk memenuhi requirement pada perancangan.

\subsection{Analisis Data Penelitian}

Pengujian dengan metode unit testing dilakukan dengan menguji tiap-tiap endpoint yang dibuat, yang kemudian dilakukan analisis terhadap output yang dihasilkan oleh endpoint tersebut. Analisis ini dilakukan dengan memperhatikan kesesuaian data dan pesan dari sebuah endpoint dan waktu proses. Pengujian dilakukan dengan melakukan request terhadap endpoint dengan http method seperti GET, POST dan PUT. Hasil pengujian terhadap setiap endpoint tersebut dipetakan seperti pada Tabel 4. Skema tabel pengujian yaitu berupa status bekerja, skenario, URL, output, dan waktu proses. Status bekerja menunjukkan keberhasilan program dari keseluruhan elemen sebuah endpoint, skenario menunjukkan bentuk uji coba yang akan dilakukan, URL menjadi alamat dari sebuah endpoint, dan output menampilkan respon yang diberikan oleh sebuah endpoint.

Tabel 4 Pengujian Uji Fungsionalitas Endpoint dengan Method POST Melakukan Login

\begin{tabular}{|c|c|c|c|c|}
\hline $\begin{array}{l}\mathrm{N} \\
\mathrm{o} .\end{array}$ & $\begin{array}{c}\text { Status } \\
\text { Bekerja } \\
\text { (Ya/Tidak) }\end{array}$ & $\begin{array}{l}\text { Skenario } \\
(1 \& 2)\end{array}$ & $\begin{array}{c}\text { URL } \\
\text { Skenario }\end{array}$ & Output \\
\hline 1. & $\mathrm{Ya}$ & $\begin{array}{l}\text { Status: } \\
200\end{array}$ & /user/login & $\begin{array}{l}\text { \{"status": 200, } \\
\text { "message": } \\
\text { "success", } \\
\text { "values": } \\
\text { "eyJhbGciOiJI } \\
\text { UzI1NiIsInR5c } \\
\text { CI6IkpXVCJ9. } \\
\text { eyJpZCI6IjUy } \\
\text { MzUxNTIyNj } \\
\text { MiLCJpYXQi } \\
\text { OjE1NjI0NzE4 } \\
\text { NDguNzE3LCJ } \\
\text { leHAiOjE1NjI0 } \\
\text { NzU0NDh9.Xs } \\
\text { f8i- } \\
\text { 06XIBMOQgll } \\
\text { aDioNqL1ObB } \\
\text {-bYqNaI4- } \\
\text { bm5MgM"\} }\end{array}$ \\
\hline 2. & $\mathrm{Ya}$ & $\begin{array}{l}\text { Status: } \\
400\end{array}$ & /user/login & $\begin{array}{c}\text { \{"status": } 400, \\
\text { "message": } \\
\text { "Wrong } \\
\text { password" } \\
\}\end{array}$ \\
\hline 3. & $\mathrm{Ya}$ & $\begin{array}{l}\text { Status: } \\
400\end{array}$ & /user/login & $\begin{array}{l}\text { \{"status": } 400, \\
\text { "message": "I" } \\
\text { username } \backslash " \text { is } \\
\text { required" }\end{array}$ \\
\hline
\end{tabular}




\begin{tabular}{|l|l|l|l|l|}
\hline 4. & Tidak & $\begin{array}{l}\text { Status: } \\
500 .\end{array}$ & /user/login & $\begin{array}{l}\text { Internal Server } \\
\text { Error }\end{array}$ \\
\hline \multicolumn{4}{|l}{ Waktu proses: $80 \mathrm{~ms}$} \\
\hline
\end{tabular}

\subsection{Pembahasan}

Pengujian dilakukan oleh penguji ahli, yaitu seorang programmer backend yang juga sebagai staff di Unit Pelayanan Teknis Teknologi Informasi dan Komunikasi (UPT TIK) bernama Muhammad Nurmansyah Santosa, S.Pd. Berdasarkan hasil pengujian pada Tabel 4.1 hingga Tabel 4.25 yang dievaluasi oleh penguji ahli, dapat dilihat bahwa hasil pengujian berjalan dengan lancar tanpa adanya kesalahan pada sisi fungsional sistem. Dengan spesifikasi personal computer yang berbeda dan dengan banyaknya aplikasi lain yang dibuka di saat pengujian, disimpulkan bahwa personal computer penelitian dengan aplikasi yang beroperasi hanya yang berkaitan dengan pengujian memiliki waktu respons lebih cepat dibandingkan dengan personal computer penguji ahli saat pengujian dengan aplikasi lain yang beroperasi selain aplikasi penelitian sebanyak 4 aplikasi. Aplikasi tersebut di antaranya Google Chrome, I Series Navigator, AnyDesk, MEmu android emulator.

Penguji ahli memberikan masukan akan urutan data keluaran yang dihasilkan agar disusun lebih teratur, agar memudahkan programmer frontend dalam mengembangkan aplikasi menjadi aplikasi yang utuh. Sehingga dapat diimplementasikan dalam pengembangan aplikasi SIAKAD yang siap digunakan oleh end user nantinya.

\subsection{Aplikasi Hasil Penelitian}

Hasil dari penelitian ini menghasilkan beberapa endpoint berdasarkan requirement milik UPT TIK dan penambahan requirement berdasarkan pada kebutuhan sistem yang disetujui oleh UPT TIK. Hasil dapat digunakan untuk web service yang akan digabungkan dengan sisi frontend untuk menghasilkan sebuah web yang utuh. Sehingga dapat memberikan acuan untuk membangun aplikasi Sistem Akademik Universitas Negeri Jakarta di masa mendatang.

\section{Kesimpulan dan Saran}

\subsection{Kesimpulan}

Web service dikembangkan dengan menggunakan framework Express.js dan daftar requirement milik UPT TIK sebagai acuan. Daftar requirement digunakan untuk memetakan endpoint, satu buah requirement dapat menghasilkan satu atau lebih endpoint dan juga beberapa requirement dapat dibuat menjadi satu endpoint.

Dalam pengembangan web service modul mahasiswa, dihasilkan 25 buah endpoint yang dihasilkan berdasarkan pada requirement. Kemudian masing-masing endpoint diuji dengan metode unit testing untuk mengetahui apakah endpoint bekerja dengan baik dan memberikan output yang sesuai dengan requirement.

Hasil pengujian fungsional dengan metode unit testing menunjukkan bahwa endpoint yang telah dibuat berfungsi dengan baik sesuai dengan skenario proses dan layak digunakan sebagai web service sebuah aplikasi.

\subsection{Saran}

Untuk pengembangan penelitian lebih lanjut disarankan untuk melakukan beberapa hal berikut:

1. Membandingkan teknologi baru yang sesuai dengan perkembangan teknologi web service.

2. Penyesuaian terhadap requirement yang mungkin saja mengalami perubahan setiap waktunya.

3. Hasil web service dapat dikembangkan dengan menerapkan prinsip frontend-backend

\section{Daftar Pustaka:}

Auth0. Introduction to JSON Web Tokens. Diambil dari https://jwt.io/introduction/. Diakses pada tanggal 28 April 2019 Pukul 16.15 WIB.

Boehm, Barry W. (1988). A Spiral Model of Software Development and Enchancement. Computer, 21(5):61-72.

Djojodihardjo, Harijono (1984). Pengantar Sistem Komputer. Jakarta: Erlangga.

Erl, Thomas., dkk. (2008). Web Service Contract Design and Versioning for SOA. New Jersey: Prentice Hall.

Hidayat, Rahmat. (2010). Cara Praktis Membangun Website Gratis : Pengertian Website. Jakarta : PT Elex Media Komputindo Kompas, Granedia.

Imelda, Erik, M (2014). Perancangan Sistem Informasi Akademik Pada Sekolah Dasar Negeri Sukajadi 9 Bandung. Jurnal Sistem Informasi Akademik, 3:47-48.

Jogianto, H.M (2005). Sistem Teknologi Informasi. Yogyakarta: Andi.

Kapojos, F., Wowor, H.F., Rumagit, A.M., Wowor, A.P.R. (2012). Implementasi Service-Oriented Architecture dengan Web Service untuk Aplikasi Informasi Akademik. Jurnal Teknik Elektro dan Komputer, 1.

Kertahadi (2007). Sistem Informasi Manajemen. Jakarta: Pustaka Binanam Pressindo.

O’Brein, James A. (2005). Pengantar Sistem Informasi. Jakarta: Salemba 4.

Oliveira, Anderson S; Serme, Gabriel; Massiera; \& Roudier, Yves. (2012). Enabling Message Security for RESTful Services. Web Services (ICWS), 2012 IEEE 19th International Conference, 
Rusdiana, H.A; \& Irfan, Moch. (2014). Sistem Informasi Manajemen. Bandung : Pustaka Setia.

Satoto, Kodrat Iman. 2009. Analisis Keamanan Sistem Informasi Akademik Berbasis Web di Fakultas Teknik Universitas Diponegoro. Di dalam: Seminar Nasional Aplikasi Sains dan Teknologi. Yogyakarta, 13 Des 2009.

Snell, James; Tidwel, Doug; \& Kuchenko, Pavel. (2001). Programming web service with SOAP. California: O'Reilly Media.

Tutorialpoints. What are web wervices?. Diambil dari https://www.tutorialspoint.com/webservice es/what_are_web_services.htm. Diakses pada tanggal 25 April 2019 Pukul 23.15 WIB.

Yuhefizar; Mooduto; \& Hidayat, R. (2009). Cara Mudah Membangun Website Interaktif Menggunakan Content Management System Joomla Edisi Revisi. Jakarta: PT Elex Media Komputindo.

Wardana. (2016). Aplikasi Website Profesional dengan PHP dan jQuery. Jakarta: Elex Media Komputindo. 